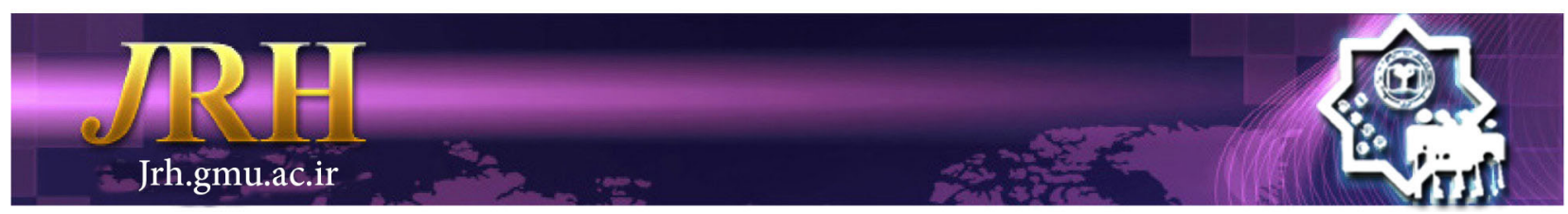

\title{
Reliability, validity, and factor structure of global measure of relationship satisfaction
}

Sayed Hadi Sayed Alitabar ${ }^{1}$, Mojtaba Habibi ${ }^{2}$, Ali Sarvestani ${ }^{3}$, Maedeh Sadat Etesami ${ }^{4}$

\author{
Journal of Research \& Health \\ Social Development \& Health Promotion \\ Research Center \\ Vol. 8, No.6, Nov \& Dec 2018 \\ Pages: $499-505$ \\ DOI: $10.29252 / j r h .8 .6 .499$ \\ Original Article
}

1. Department of Psychology \& Educational Sciences, Faculty of Counseling, Isfahan University, Isfahan, Iran

2. Correspondence to: Department of Health Psychology, School of Behavioral Sciences and Mental Health (Tehran Institute of Psychiatry), Iran University of Medical Sciences, Tehran, Iran

Email: Habibi.m@iums.ac.ir

3. Department of Psychology \& Educational Sciences, Faculty of Counseling, Shahid Beheshti University, Tehran, Iran

4. Department of Psychology \& Educational Sciences, Faculty of Counseling, Pharabi Paradise, University of Tehran, Tehran, Iran

Received: 23 Jan 2015

Accepted: 14 Nov 2015

How to cite this article: Sayed Alitabar SH, Habibi M, Sarvestani A, Etesami MS. Reliability, validity, and factor structure of global measure of relationship satisfaction. $J$ Research \& Health2018; 8(6): 499- 505.

\begin{abstract}
Reproduction of scoring and interpretation of conceptual model underlying global measure of relationship satisfaction (GMREL) scale are prerequisites to the use of it in cross-cultural studies. This study was carried out to examine the factor structure and the psychometric properties of the Iranian version of GMREL. The participants of this study consisted of 299 patients (men=128 and women=171) who attended to counseling centers in Tehran. The GMREL, attitudes toward infidelity scale, Kansas marital satisfaction scale, and Enrich sexual satisfaction subscale were used for data collection. Results supported the internal consistency, test re-test reliability, and concurrent validity of GMREL. The confirmatory factor analysis of data supported first-order factor model includes 6 items. Our results confirmed the predicted relationships between GMREL and attitudes toward infidelity, marital satisfaction, and sexual satisfaction and also revealed the construct validity of GMREL translation among Iranian population. This study showed that GMREL has appropriate validity and reliability for Iranian sample and can be used as reliable, valid, and cross-cultural instrument.
\end{abstract}

Keywords: Factor Structure, Reliability, Satisfaction, Validity

\section{Introduction}

Interpersonal communications are the basis and foundation of identity and human maturation. Efficient communications lead to self-actualization and can improve the quality of relationships where inefficient ones hurt personal relationships. Therefore, interpersonal communications have key role in human life [1]. One of the most important interpersonal communications is relationship between spouses. Satisfaction and quality of this relationship can influence mental and physical health of spouses dramatically [2].

Marital satisfaction can result in couples' happiness and adjustment in different aspects of their life, empowers the family structure, and also guarantees its wellbeing [3]. Marital satisfaction is critical in balancing family life and the emotional atmosphere and can be an effective factor for dealing with stress and having a good performance in life [4]. Moreover, various studies have indicated that marital satisfaction leads individuals to be happier and healthier than others [5]. Markman and Floyd [6] suggested that most of married people have a high level of marital satisfaction at the beginning of their marriage, but in addition to the gradual decline that occurs over time in marital, serious problems also occur in the first weeks and months of marriage if not resolved can threaten the marital relationship satisfaction and stability. On the other hand, previous studies showed 
that at the present time couples are faced with numerous problems and inconsistencies in establishing and maintaining intimate relationships and marital satisfaction [7] and feeling safe, calmness, and intimacy between spouses have declined and family life has turned to unpleasant processes. For instance, some research demonstrated that marital satisfaction among women is less than men [8] and this factor make more vulnerable married women to psychological distress in comparison with single women [9]. Hence, there is serious need for a valid instrument to measure relationship satisfaction among married couples more than ever for better understanding of relationships and help spouses to enrich and improve their interactions [10-13].

A number of tools have been proposed for the evaluation of quality of life, including Kansas marital satisfaction scale [14] (3 items) and marital quality index [15] (6 items) as some of short-term instruments. Dyadic adjustment scale [16] (32 items) and sexual satisfaction scale [17] (48 items) are long-term singlefactor indexes for assessing life quality. Sexual satisfaction questionnaire (280 items) was introduced by Schneider [13] and assesses multiple aspects or multiple factors of marital satisfaction. Most of these instruments are too long. Therefore, shorter questionnaire seemed necessary which can cover all aspects of family issues, including marital satisfaction. One of the short-term instruments for examining marital satisfaction is Global Measure of Relationship Satisfaction (GMREL).

This scale was introduced by Byers, Demmons, and Lawrance [18]. Previous studies confirmed its appropriate validity and reliability [19-22]. One of its privileges over ENRICH marital satisfaction scale is that participants can respond questions in shorter time with less energy. Another advantage of short-term questionnaire in comparison with longer ones is that they let psychologists and family therapists to gather valuable data about marital satisfaction of couples and find appropriate strategies in order to overcome family difficulties. Since each of the spouses with different ideas and beliefs starts married life, dissatisfaction occurs in a variety of fields which are basis for the next family problems. Making valid and reliable tools can help psychologist and family counselor for early diagnosis.

The two main goals of this study were to assess factor structure of GMREL on married men and women by using confirmatory factor analysis and to examine validity and reliability of GMREL.

\section{Method}

The participants included all married men and women who referred to counseling centers of Tehran. The participants had married for at least one year. Six centers randomly were selected among 12 counseling centers in district 2 Tehran and 299 participants (128 men, 171 women) were selected by convenience sampling method. In this study, Cohen's d formula was used to determine the accurate sample size [23]. Data were gathered using survey method (questionnaire).

GMREL: It is a self-report questionnaire consisted of 6 items measures an individual's relationship satisfaction with his/her current partner. For example, the participants were asked "In general, how would you describe your overall relationship with your partner?". The participants answered the questions based on 7 rates on Likert scale which assesses two completely different dimensions for each question (e.g. completely unsatisfied/ perfect $\neg$, Good/Bad, Pleasant/Unpleasant, Positive/Negative, Satisfied/Unsatisfied, and Valuable/Worthless). The range of scores varies from 6 to 42. Higher scores mean more satisfaction in relationship. For all respondents, all six items have to be summed up to obtaon total score of GMREL. The internal consistency coefficient of this scale (Cronbach's Alpha) is 0.95 and it also has appropriate validity and high retest reliability [19-22]. In another research, its internal consistency coefficient was reported 0.96 [24].

Attitudes Towards infidelity Scale (ATIS): This scale includes 12 items which are scored in 
range of "strongly agree" (score 7) to "strongly disagree" (score 1). Whatley's [25] findings showed acceptable validity, reliability, and its internal consistency coefficient (Cronbach's alpha $=0.80)$.

Kansas Marital Satisfaction Scale (KMSS): This scale has been used vastly in studies [2628]. This scale has only 3 items. Despite that it is short-term questionnaire, it has divergent validity [29]. KMSS has adequate concurrent validity with Dyadic Adjustment Scale (DAS) [16] and Quality Marriage Inventory (QMI) [15]. Specifically, Schumm et al. [14] have obtained re-test coefficient of $\mathrm{r}=0.83$ for women and $\mathrm{r}=0.91$ for men in Kansas and Quality Marriage scales. Weigel and Ballard-Reisch [29] gained internal consistency coefficient of 0.97 for men and women (Cronbach's Alpha) in their study by using Kansas scale. Schumm et al. [30] obtained alpha between 0.84 and 0.98 in a study on married couples. Obtained Cronbach's Alpha was estimated 0.92 for this test in Iran [31].

Enrich Sexual Satisfaction: Sexual satisfaction has been studied by 10 items of Enrich sexual relationship scale [32]. These 10 items measure emotions about sexual and affective relationships. These items reflect individual's attitude toward sexual issues, sexual behavior, and sexual fidelity. Fowers \& Olson [33] have obtained $\mathrm{r}=0.85$ for internal consistency coefficient (Cronbach's Alpha) along with retest reliability of 0.92 (4 week intervals) for sexual relationship scale. Sexual relationships, relationship quality and problem solving among 10 subscales of Enrich are three main predictors able to assess divergent validity to distinguish satisfied individuals from unsatisfied ones [33]. GMREL was translated to Farsi, and then the Farsi version was back translated to English by somebody else. Then, two English versions were compared. Final translation was studied by 7 psychology and counseling professors. These professors studied the comprehensibility of questions; that is, whether the questionnaire covered all the aspects of the issue; they also examined the appearance of the questionnaire. Next, the items of questionnaire was read one by one to a concentrated group consisted of 10 married men and 10 married women and any ambiguity in any item was discussed and amended. After all these phases, the questionnaire was distributed among over-ayear married men and women. The outcomes were analyzed by LISREL-8.80 and SPSS- 22 .

\section{Results}

The statistical population of this study consisted of 229 partisipants; 171 women $(\% 57.2)$ and 128 men $(\% 42.8)$ which were selected by convenience sampling method. Maximum and minimum age of participants were 17 and 62, respectively (Mean=31.82, Range $=45)$ and there were 101 participants with high school diploma or less (\%33.8), 28 with associate diploma (\%9.4), 106 with B.A. /B.S. (\%35.5), 64 with M.A. /M.S. or above (\%21.4).

Before studying fitting of measuring model, several assumptions including: 1) Normal distribution of variables 2) Multiple observed variables (At least 2 observed variables for each hidden variable) 3) Over identified model 4) Interval measurement scale were studied [34] were considered. For the first assumption, results of univariate and multivariate normality test were checked by LISREL. Since normality of some of the variables was not proved, the resistant estimation method was used against violation of normality, thai is discussed in parameters assessment section. Based on LISREL outcomes and fitting of measuring models, "over identified model" and "not multicollinearity" assumptions were regarded among other variables and finally the "interval measurement scale" assumption was confirmed.

As first step, the fitting of measuring model of data was assessed by LISREL-8.80 [35]. The assessed model was consisted of Byers, Demmons, and Lawrance [18] single factor model by loading 6 questions on one factor of GMREL. Considering the violation of normal distribution assumption, maximum likelihood robust procedure was used against normal distribution assumption to assess the model 
and the following indexes were used for fitting of the model: Satorra-Bentler chi-square index $\left(\mathrm{x}^{2}\right)$, chi-square over Degree of Freedom index $\left(x^{2} / D F\right)$, Goodness of Fit Index (GFI), Adjusted goodness of fit index (AGFI), Comparative Fit Index (CFI), Root Mean Square Error of Approximation (RMSEA), Root Mean Square residual (RMR).

Table 1 Findings of confirmatory factorial analysis of GMREL scale

\begin{tabular}{|c|c|c|c|c|}
\hline Items & Factor loadings & S.E. & t value & $\mathrm{R}^{2}$ \\
\hline $\begin{array}{l}\text { 1- In general, how would you describe your overall relationship with your } \\
\text { partner? } \\
\text { (Completely unsatisfied/..../perfect) }\end{array}$ & 0.80 & 0.06 & 17.51 & .64 \\
\hline $\begin{array}{l}\text { 2- In general, how would you describe your overall relationship with your } \\
\text { partner? } \\
\text { (very bad/..../very good) }\end{array}$ & 0.92 & 0.05 & 24.99 & .85 \\
\hline $\begin{array}{l}\text { 3- In general, how would you describe your overall relationship with your } \\
\text { partner? } \\
\text { (very unpleasant } / . . . . / \text { very pleasant) }\end{array}$ & 0.82 & 0.06 & 20.01 & .67 \\
\hline $\begin{array}{l}\text { 4- In general, how would you describe your overall relationship with your } \\
\text { partner? } \\
\text { (very negative/..../very positive) }\end{array}$ & 0.95 & 0.05 & 26.42 & .90 \\
\hline $\begin{array}{l}\text { 5- In general, how would you describe your overall relationship with your } \\
\text { partner? } \\
\text { (very unsatisfying/..../very satisfying) }\end{array}$ & 0.94 & 0.05 & 26.67 & .89 \\
\hline $\begin{array}{l}\text { 6- In general, how would you describe your overall relationship with your } \\
\text { partner? } \\
\text { (worthless/.../very valuable) }\end{array}$ & 0.94 & 0.05 & 26.03 & .89 \\
\hline
\end{tabular}

In Table 1, outcomes of confirmatory factorial analysis of GMREL scale questions have been presented as ParameterEstimation(PE), Standard Error of parameter Estimation (SE) and t value to analyze the significance of parameter and $\mathrm{R}^{2}$ of each question on the related parameter. The analysis of the parameter values showed their acceptability (P.E. $<0.3$ )

Table 2 Indexes of confirmatory factor analysis of GMREL

\begin{tabular}{lccccccc}
\hline Satorra-Bentler $\mathrm{X}^{2}$ & Df & $\mathrm{X}^{2} / \mathrm{df}$ & GFI & AGFI & CFI & RMSEA & RMR \\
\hline 11.82 & 7 & 1.68 & 0.98 & 0.93 & 0.98 & 0.04 & 0.05 \\
\hline
\end{tabular}

Analyzing the differences in fitting of model showed that this model fits data appropriately; therefore, the outcomes confirmed inclined onefactor model. Analysis of fitting of model indexes indicated that the mentioned model fits data rather favorably. If CFI, AGFI, GFI were over .95 and RMSEA and RMR were less than 0.05 , the fitting would be very desirable and would have very good fitting and if CFI, AGFI, GFI were over 0.90 and RMSEA and RMR were less than 0.08 , it means a good and desirable fitting [36-38]. Hence, CFI, GFI, and RMSEA showed very desirable and very good fitting and AGFI and RMR indicated good and desirable fitting and based on chi-square over degree of freedom index, the fitting is extremely acceptable (Table 2). Therefore, according to the results obtained by the first order of measurement model, it can be concluded that GMREL Measurement Models enjoy suitable validity to be used on society of the research.

Cronbach's Alpha and re-test coefficient were used to determine the reliability of this scale. Cronbach's Alpha of GMREL Scale was calculated as 0.95 and the re-test coefficient obtained 0.89 during 8 days intervals.

The construct validity (Divergent and convergent) was used to study the validity of this test. According to Sarmad et al. [39], if the correlation between scores of tests measuring unique trait were remarkable, the test will have convergent validity and if the correlation between the ones measuring different traits was low, the test will have discriminant validity or is divergent. KMSS and ENRICH sexual satisfaction subscale were used to study 
convergent validity, and ATIS was applied to study the divergent validity (Table 3)

Table 3 Convergent and divergent validity coefficient of GMREL

\begin{tabular}{lccc}
\hline Factor & KMSS & ENRICH sexual satisfaction & ATIS \\
\hline Global relationship satisfaction & $0.73^{* *}$ & $0.52^{*}$ & $-0.14^{* *}$ \\
\hline$\alpha=0.01^{*} \alpha=0.05^{* *}$ & & &
\end{tabular}

Age

The relation between age and relationship satisfaction was studied using Pearson correlation coefficient to examine this transaction. Regarding the obtained results and considering that the $r$ amount of relation between age and relationship satisfaction was not significant ( $\mathrm{r}=-.11, \mathrm{~N}=299)$, it can be said that there is no significant relation between these two variables $(\mathrm{p}>0.05)$

Gender

Results in Table 4 indicate a is significant difference between Married Men ( $\mathrm{M}=28.83)$ and Married women $(M=27.19)$ concerning mean of Global Relationship Satisfaction ( $\mathrm{t}$ $(299)=2.22, \mathrm{p}<0.05)$.

Table 4 Difference between 2 groups of men and married women in terms of global relationship satisfaction means

\begin{tabular}{lccccccc}
\hline Variable & Group/statistic & Sample size & Mean & SD & t & df & p-value \\
\hline \multirow{2}{*}{ Global relationship satisfaction } & Men & 128 & 28.83 & 5.86 & 2.22 & 297 & .02 \\
& Women & 171 & 27.19 & 6.65 & & & \\
\end{tabular}

\section{Education}

The F test was applied to compare mean scores of global relationship satisfaction scores in 4 education groups (High school diploma and less, associate diploma, Bachelor of Arts/
Bachelor of Science, Master of Arts/Master of Science, and above). The calculated F was 0.98 , so there is no significant difference among 4 educational groups concerning global relationship satisfactions across $(\mathrm{p}>0.05)$.

Table 5 One-way ANOVA in 4 education groups

\begin{tabular}{lccccc}
\hline Source of differences & Sum of squares & Df & Mean of squares & F & p-value \\
\hline Between Groups & 120.88 & 3 & 40.29 & 0.98 & 0.39 \\
Within Groups & 11959.65 & 293 & 40.81 & & \\
Total & 12080.54 & 296 & & & \\
\hline
\end{tabular}

\section{Discussion}

The purpose of this study was to determine psychometric features and factor structure of GMRS among married men and women in Tehran. The outcomes of this study indicated the acceptable validity and reliability of the selected scale for estimating the relationship satisfaction among Iranian. The obtained results on relationship satisfaction scale revealed its internal consistency (Cronbach's Alpha= 0.95). This study is consistent with Lawrence [19], Byers [20], and Byers [21]. Based on aforementioned studies, the reliability of this instrument is 0.86 to 0.95 using Cronbach's Alpha. The gained validity coefficient (0.98) was also acceptable and desirable.

In this study, the GMREL was used to evaluate confirmatory factor structure of the first order. The single-factor structure of the first order of GMREL had fitted observed data in better way. Lawrance and Byers [19,20] also indicated acceptable factor structure of the GMREL. The validity, reliability, and confirmatory factor structure of GMREL was acceptable for researches and clinical diagnosis. Anyway, according to the obtained data, GMREL can be trustworthy and valid scale to assess Iranian families to gather constant and stable results.

Reverse correlation between "total score of GMREL " and ATIS used to study divergent validity. As we know, GMREL theoretically investigates behaviors which are different from attitudes towards infidelity scale; therefore, the negative correlation between this test and two other subscales in this study confirmed favorable divergent validity of this scale. In the 
same way, positive and almost high correlation among GMREL, KMSS and ENRICH sexual satisfaction subscale indicated the acceptable convergent validity of this scale. These findings confirm the findings of Lawrance and Byers [22]. The results of analysis on interaction of demographic variables and GMREL also showed no significant correlation between age and relationship satisfaction which means that global satisfaction does not varies among different ages. This finding is in consistent with Attari et al.'s study [40]. On the other hand, the findings of this study indicated a significant relation between gender and global relationship satisfaction. Hence, men are more satisfied with their marriage than women. This finding is consistent with Fowers [8] who reported that women are less satisfied with their marriage than men. In this study, there was no relationship between education and marriage satisfaction, in other words, highly educated individuals were as satisfies with their marriage as ones with lower education. The lack of difference demonstrated that considering only education cannot be a sign of higher culture and then a key factor for better adjustment in marriage. Even sometimes, as much as in higher educational level, people's expectations also rise which can be counted as damaging factor to the success of marital relationship.

There are some limitations with this study. First, using self-report instruments (instead of observing real behaviors) may lead participants to respond in a way consistent with social acceptance and try to avoid the discredit of individual inefficiency, just like most of other studies. Second, the population of this study only included married men and women in Tehran and people from other cities, with other occupations, and from other social levels were absent.

\section{Conclusion}

With respect to findings of current investigation, GMREL Scale can be used individually or in groups as a diagnostic instrument in family consultant and couple therapy. This instrument can also be applied in different areas such as marital issues and family and interpersonal close relationship.

\section{Contribution}

Study design: $\mathrm{MH}$

Data collection and analysis: MH, SHSA, AS

Manuscript preparation: SHSA, AS, MSE.

\section{Acknowledgments}

We do appreciate patience of all participants who cooperated during this study.

\section{Conflict of Interest}

"The authors declare that they have no competing interests."

\section{Funding}

The author (s) received no financial support for the research, authorship and/or publication of this article.

\section{References}

1- Wood JT. Interpersonal communication: everyday encounters, Wasdworth publishing company. 2 edition. Belmont, CA: Wadsworth pub; 1999.

2- Campbell LT. The effectiveness of family interventions for physical disorders. J Marital Fam Ther2003; 29(2): 2003: 263-81.

3- Asgarifar H. The role of mental health in marriage, life \& divorce. Tehran; Goftogoo press; 2001.

4- Floyd FJ, Gilliom L A, Costigan CL. Marriage and the parenting alliance: longitudinal prediction of change in parenting perceptions and behaviors. Child Dev1998; 69(5): 1461-79.

5- Donnelly AD. Sexually inactive marriages. J Sex Res 1993; 30(2): 171-9.

6- Markman JH, Floyd F. Possibilities for the prevention of marital discord: A behavioral perspective. Ame J Fam Ther1980; 8(2): 29-48.

7- Bernshtein FH, Bernshtein MT. Recognition \& therapy of marital conflict: marital therapy. Oxford: Oxford university press; 1989.

8- Fowers JB. His and here marriage: a multivariate study of gender and marital satisfaction. Sex Roles 1991; 24(3-4): 209-21.

9- Bernard J. The future of marriage. New York: Bantam; 1975.

10- Sabatelli MR. Measurement issues in marital research: a review and critique of contemporary survey instruments. J Marriage Fam1988; 50(4) 891-915.

11- Fowers BJ. His and her marriage: a multivariate study of marital satisfaction. Sex Roles 1991; 24(3): 
209-21.

12- Edmonds VH. Marital conventionalization: Definition and measurement. J Marriage Fam1967; 29(4): 681-8.

13- Snyder DK. Multidimensional assessment of marital satisfaction. J Marriage Fam1979; 41(4): 813-23.

14- Schumm WR, Paff-Bergen LA, Hatch RC, et al. Concurrent and discriminant validity of the kansas marital satisfaction scale. J Marriage Fam1986; 48(2): 381-7.

15- Norton R. Measuring marital quality: a critical look at the dependent variable. J Marriage Fam1983; 45(1): $141-51$.

16- Spanier GB. Measuring dyadic adjustment: new scales for assessing the quality of marriage and similar dyads. J Marriage Fam1976; 38(1): 15-28.

17- Butzer B, Campbell L. Adult attachment, sexual satisfaction, and relationship satisfaction: a study of married couples. Pers Relat2008; 15(1): 141-54.

18- Byers SE, Demmons S, Lawrance K. Sexual satisfaction within dating relationships: a test of the interpersonal exchange model of sexual satisfaction. $J$ Soc Pers Relat1998; 15(2): 257-67.

19- Lawrance K, Byers SE. Sexual satisfaction in long-term heterosexual relationships: the interpersonal exchange model of sexual satisfaction. Pers Relat1995; 2(4): 267-85.

20- Lawrance K, Byers SE. Interpersonal exchange model of sexual satisfaction questionnaire. In Davis CM,Yarber WL, Baureman R, Schreer G, Davis SL, eds. Sexuality related measures: a compendium, 2nd ed. Thousand Oaks, CA: Sage; 1998. pp: 514-9.

21- Byers SE. Relationship satisfaction and sexual satisfaction: a longitudinal study of individuals in longterm relationships. J Sex Res2005; 42(2) 113-8.

22- Weaver AD, Byers SE. The relationships among body image, body mass index, exercise, and sexual functioning in heterosexual women. Psychol Women Q2006; 30(4): 333-9. 23- Whatley MA. Attitudes toward infidelity scale. J Soc Psychol2008; 133: 547-51.

24- Grover KJ, Russell CS, Schumm WR, et al. Mate selection processes and marital satisfaction. Fam Relat 1985; 34: 383-6.

25- Morris ML, Blanton PW. The influence of workrelated stressors on clergy husbands and their wives. Fam Relat1994; 43(2): 189-95.

26- Hunsley J, Pinsent C, Lefebvre M, et al. Construct validity of the short forms of the dyadic adjustment scale.
Fam Relat1995; 44(3): 231-7.

27- Schumm WR, Nichols CW, Schectman KL, et al. Characteristics of responses to the Kansas marital satisfaction scale by a sample of 84 married mothers. Psychol Rep 1983; 53: 567-72.

28- Weigel DJ, Ballard-Reisch DS. Using paired data to test models of relational maintenance and marital quality. J Soc Pers Relat1999; 16(2): 175-91.

29- Schumm WR, Scanlon ED, Crow CL, et al. Characteristics of the Kansas marital satisfaction scale in a sample of 79 married couples. Psychol Rep1983; 53(2):583-8.

30- Sayed Alitabar SH, Mohammad Alipour Z, Habibi F, Sarvestani A, Javanbakht A. Reliability, validity and factor structure of the marital disillusionment scale. Pajoohande2016; 20(6): 342-9.

31- Fowers BJ, Olson DH. ENRICH marital satisfaction scale: a brief research and clinical tool. J Fam Psychol1993; 7(2): 176-185.

32- Mitchell SE, Newell GK, Schumm WR. Test-retest reliability of the Kansas marital satisfaction scale. Psychol Rep1983; 53(2): 545-6.

33- Fowers BJ, Olson DH. ENRICH marital inventory: a discriminant validity and cross-validation assessment. J Marital Fam Ther1989; 15(1): 65-79.

34- Hayduk LA. Structural equation modeling with LISREL. Baltimore: Johns Hopkins; 1987.

35- Joreskog KG, Sorbom D. LISREL 8: user's reference guide. Chicago: scientific software international. Inc Chicago: Scientific software international; 1996.

36- Bentler PM. Comparative fit indexes in structural models. Psychol Bull1990; 107(2): 238-46.

37- Tabachnick BG, Fidell LS. Using multivariate statistics (5th ed). New York: Harper collins; 2007.

38- Hu L, Bentler PM. Cutoff criteria for fit indexes in covariance structure analysis: conventional criteria versus new alternatives. Struct Equ Modeling1999; 6(1): 1-55.

39- Sarmad Z, Bazargan A, Hejazi E. Research methods in behavioral sciences. Tehran: Agah publication; 2012. 40-AttariY,AmanollahifardA, Mehrabizade Honarmand M. Investigate the relationship between personality characteristics and interpersonal factors-family and marital satisfaction in government offices in Ahwaz. Journal of Educational Science Psychology2006; 13(3): 81-108.

\footnotetext{
Copyright $\odot 2016$ ASP Ins. This open-access article is published under the terms of the Creative Commons Attribution-NonCommercial 4.0 International License which permits Share (copy and redistribute the material in any medium or format) and Adapt (remix, transform, and build upon the material) under the Attribution-NonCommercial terms.
} 